\title{
Highly increased CSF tau protein and decreased $\beta$-amyloid (1-42) in sporadic CJD: a discrimination from Alzheimer's disease?
}

\author{
E Kapaki, K Kilidireas, G P Paraskevas, M Michalopoulou, E Patsouris
}

\begin{abstract}
The aim was to quantify tau protein and $\beta$-amyloid (A $A 42)$ in the CSF of patients with sporadic Creutzfeldt-Jakob disease (CJD), Alzheimer's disease (AD), and controls. Double sandwich enzyme linked immunosorbent assays (ELISAs) were used for measurments. Tau was increased 58-fold in CJD and 3.5-fold in AD compared with controls, whereas Aß42 was decreased 0.5 -fold in both CJD and AD. A cut off level for tau protein at $2131 \mathrm{pg} / \mathrm{ml}$ successfully discriminated CJD from AD (100\% specificity and $93 \%$ sensitivity). Tau protein concentration in CSF is probably an additional useful marker in differentiating CJD from AD.

(F Neurol Neurosurg Psychiatry 2001;71:401-403)
\end{abstract}

Keywords: Creutzfeldt-Jakob disease; Alzheimer's disease; tau protein; $\beta$-amyloid 1-42

Sporadic Creutzfeldt-Jakob disease (CJD) is a rare and fatal human neurodegenerative disorder belonging to the transmissible spongiform encephalopathies or prion diseases. The classic triad of the clinical syndrome consists of rapidly progressive dementia, myoclonus, and a characteristic EEG. Diagnosis can only be definite at postmortem examination or brain biopsy showing the pathological isoform of the prion protein $\left(\mathrm{PrP}^{\mathrm{sc}}\right){ }^{1}$ Alzheimer's disease (AD) is the most common condition mimicking CJD, sharing some clinical and neuropathological features. Among several biomarkers, recently being evaluated for $\mathrm{AD}$, the microtubule associated tau protein and the $\beta$-amyloid 1-42 (A $\beta 42)$, a constituent of senile plaques, are the most reliable. Increased CSF tau protein concentrations and decreased $\mathrm{A} \beta 42$ concentrations have been found in $\mathrm{AD}$ and have been proposed as candidate diagnostic markers. ${ }^{2-4}$ Neuronal loss with collapse of the cytoarchitecture is common in both diseases. Amyloid plaques are seen in up to $10 \%$ of patients with $\mathrm{CJD}^{1}$ and occasionally true $A \beta$ deposits have been reported. ${ }^{5}{ }^{6}$ Due to these similarities of the two diseases we examined the above markers in patients with neuropathologically confirmed CJD, patients with well documented $\mathrm{AD}$, and age matched normal controls.
Patients and methods

A total of 99 subjects were included in the study: 14 patients with CJD, 38 patients with $\mathrm{AD}$, and 47 controls. The clinical diagnosis of CJD was based on progressive dementia of less than 2 years, periodic sharp wave complexes in the EEG recording, and two of the following: (1) myoclonus, (2) visual or cerebeller symptoms, (3) pyramidal or extrapyramidal tract signs, and (4) akinetic mutism. All patients had a positive test for 14-3-3 protein, a sensitive marker of the disease. Twelve out of the 14 patients were confirmed either postmortem or by biopsy as definite cases of CJD. The diagnosis of AD was based on the NINCDS-ADRDA criteria for probable $\mathrm{AD}{ }^{7}$ The control group comprised 47 elderly subjects who underwent hernia repair under spinal anaesthesia, without any history, symptoms, or signs of cognitive disorder or other neurological, malignant, or systemic disease.

Samples of CSF were obtained by lumbar puncture after consent. They were centrifuged immediately and stored in polypropylene tubes at $-80^{\circ} \mathrm{C}$ until analysis. Tau and $\mathrm{A} \beta 42$ concentrations in CSF were measured in duplicate by double sandwich enzyme linked immunosorbent assay (ELISA) using the Innotest htau antigen kit and the Innotest $\beta$-amyloid (1-42) kit, according to the manufacturer's (Innogenetics, Gent, Belgium) instructions. Freezing and thawing of samples were avoided. The intra-assay and interassay variabilities for tau protein were $8 \%$ and $9 \%$ respectively, and the corresponding variations for $\mathrm{A} \beta 42$ were $7 \%$ and $10 \%$ respectively. A Kruskal-Wallis test followed by Dunn's multiple comparison test was used to compare tau protein and $A \beta 42$ concentrations among the groups. The Spearman correlation coefficient was used for correlations. Receiver operating characteristics (ROCs) curve analysis, was used to define the cut off concentrations of tau protein and $A \beta 42$ with the corresponding optimal sensitivity and specificity.

\section{Results}

Results are summarised in table 1. Age, sex, disease duration, and age of disease onset did not affect tau protein and $A \beta 42$ in any of the groups. Patients with CJD showed markedly 
Table 1 Clinical and biochemical data of the studied groups

\begin{tabular}{|c|c|c|c|c|}
\hline & Controls & $A D$ & $C f D$ & p Value \\
\hline No of patients & 47 & 38 & 14 & \\
\hline $\mathrm{Sex}^{\star}$ & $29 / 18$ & $15 / 23$ & $7 / 7$ & NS \\
\hline Age $(y) \dagger$ & $65(10)$ & $68(10)$ & $59(4)$ & 0.012 \\
\hline Disease duration $(y) \dagger$ & & $3.6(2.4)$ & $0.4(0.2)$ & \\
\hline $\mathrm{Tau}(\mathrm{pg} / \mathrm{ml}) \ddagger$ & $137(110-220)$ & $490(366-796)$ & $7942(3787-14750) \int$ & $<0.0001$ \\
\hline $\mathrm{A} \beta 42(\mathrm{pg} / \mathrm{ml}) \ddagger$ & $734(521-865)$ & $375(320-440)$ & $312(218-511)$ & $<0.0001$ \\
\hline
\end{tabular}

${ }^{\star}$ Men/women, comparison with $\chi^{2}$ test. $†$ Mean (SD); age compared with one way ANOVA. $¥$ Median (quartiles), comparison with Kruskal-Wallis test. $\$$ Minimum $=1240$, maximum $=26570$. $\lceil\mathrm{n}=12$.

increased tau protein $(\mathrm{p}<0.001)$ and significantly decreased $A \beta 42(p<0.001)$ compared with controls. Patients with AD also had significantly increased tau protein $(\mathrm{p}<0.001)$ and significantly decreased $\mathrm{A} \beta 42 \quad(\mathrm{p}<0.001)$ compared with controls. No difference in tau protein and $A \beta 42$ concentrations were detected between early (duration $<2$ years) and late AD. Patients with CJD had significantly increased tau protein $(\mathrm{p}<0.01)$, but similar values in $\mathrm{A} \beta 42$ as patients with $\mathrm{AD}$. For $\mathrm{AD}$ versus controls, the optimal cut off concentration for tau protein suggested by ROCs was $295 \mathrm{pg} / \mathrm{ml}$ (fig $1 \mathrm{~A}$ ) and the specificity and sensitivity were $91.5 \%$ and $89.5 \%$ respectively. The optimal cut off level for A $\beta 42$ was 445 $\mathrm{pg} / \mathrm{ml}$ (fig $1 \mathrm{~B}$ ), resulting in a specificity of $85 \%$ and a sensitivity of $76 \%$. For CJD versus $A D$, the optimal cut off level for tau protein at 2131 $\mathrm{pg} / \mathrm{ml}$ resulted in $100 \%$ specificity and $93 \%$ sensitivity. A significant negative correlation between tau protein and $A \beta 42$ was found in patients with CJD (fig 2), but not in patients with $\mathrm{AD}$ and controls.

\section{Discussion}

The results of the present study have shown an extremely marked increase in tau protein and a 0.5 -fold decrease in $\mathrm{A} \beta 42$ in the CSF of patients with CJD compared with controls. Patients with CJD also had significantly increased tau protein compared with patients with $\mathrm{AD}$. This is the first report of combined analysis of tau protein and A $\beta 42$ in CJD and the first comparative study versus $\mathrm{AD}$ and normal controls for both markers. Previous studies of combined analysis of these markers in $\mathrm{AD}$ have suggested that high tau protein and low A $\beta 42$ is a characteristic profile of AD. However patients with CJD presented with a multifold increase in tau protein beyond the range seen in $\mathrm{AD}$ or in other dementing disorders. With the cut off point of $2131 \mathrm{pg} / \mathrm{ml}$, all except one patient were discriminated from either patients with $\mathrm{AD}$ or the controls. The only patient that fell in the range of the $\mathrm{AD}$ group was a patient with probable CJD with a relatively weaker 14-3-3 protein band, not yet having been confirmed pathologically.

Our results for tau protein are in agreement with the results of Otto et $a l^{\beta}$ who studied patients with CJD versus patients with other dementing and non-dementing neurological disorders, and also support the notion of tau protein being a sensitive marker for CJD. We specified $2131 \mathrm{pg} / \mathrm{ml}$ as the optimal cut off level for $\mathrm{AD}$, the main disease in CJD differential diagnosis. A decrease in $A \beta 42$ was in the range of the $\mathrm{AD}$ group. Low $\mathrm{A} \beta 42$ values in $\mathrm{CSF}$ have been reported in $\mathrm{CJD}^{9}$ in one recent study and also in $\mathrm{AD}$ and other dementing disorders, ${ }^{10}$ suggesting that a decrease in $\mathrm{A} \beta 42$ is not a specific marker.
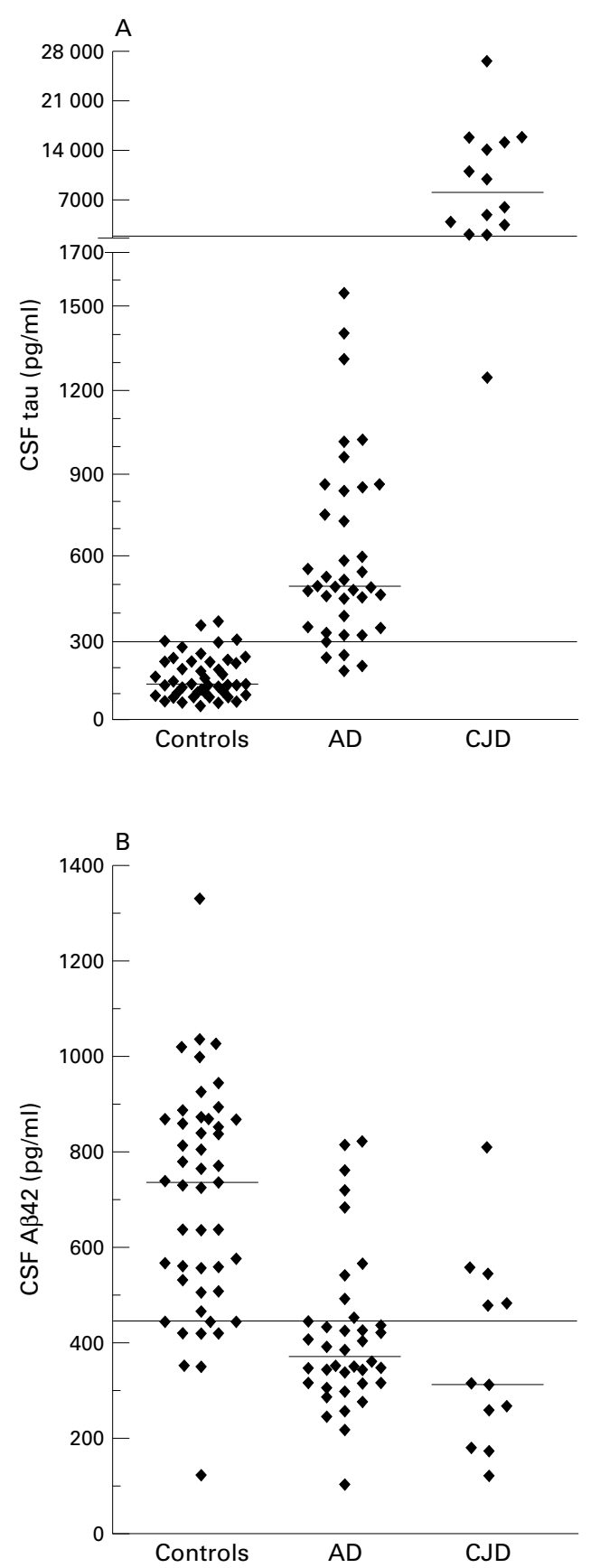

Figure 1 Concentrations of CSF tau protein $(A)$ and $A \beta 42(B)$ in the groups studied. Horizontal bars indicate median values and horizontal lines indicate cut off concentrations suggested by ROC analysis. 


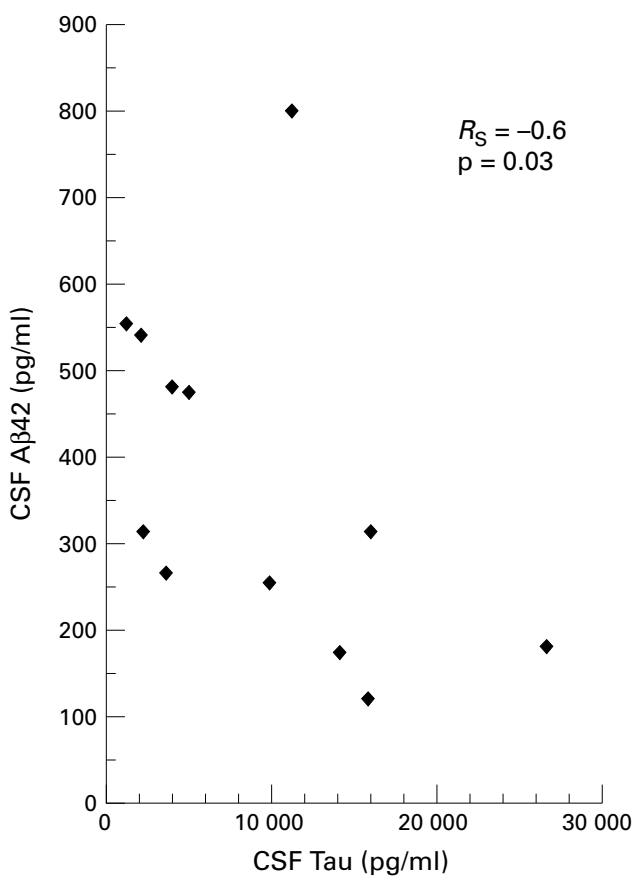

Figure 2 Significant negative correlation between CSF tau protein and $A \beta 42$ in $C F D(n=12)$.

The release of both tau protein and $\mathrm{A} \beta 42$ into CSF is considered to be a normal process, as they are detectable in normal subjects; however, the nature of these markers in CSF and their relation to neuropathology of different diseases has not been well documented. High concentrations of tau protein had at first been associated with neurofibrillary lesions, and it has been suggested that concentrations of tau protein in CSF is related to the number of tangles in patients with $\mathrm{AD} .{ }^{11}$ However, a high CSF tau protein concentration has also been reported in diseases without neurofibrillary pathology. ${ }^{12}$ The very high concentrations of tau protein in patients with CJD are possibly correlated to the rapidly occurring neuronal loss. Our knowledge on the biochemical characteristics of CSF tau protein molecules among diseases (three versus four repeat tau protein) is also limited. The phosphorylation state is another matter under investigation as the available test cannot discriminate normal from phosphorylated tau protein.

$\beta$-Amyloid, the product of the proteolytic processing of amyloid precurses protein (APP), is constitutively secreted into the extracellular space which is in continuum with CSF.
Biochemical studies have shown that the A $\beta 42$ peptide aggregates far more rapidly into amyloid fibrils than other species, such as $\mathrm{A} \beta 40 .{ }^{13}$ The mechanism(s) underlying $\mathrm{A} \beta 42$ reduction in the CSF is not known. Possible hypotheses include increased aggregation into insoluble fibrils (at least in AD), decreased production, implication of other unknown factors regulating cellular APP processing, and failure of detection by current methodology due to masked epitopes. ${ }^{9}$ In the present study, the inverse correlation between tau protein and A $\beta 42$ only in patients with CJD suggests a common mechanism affecting both substances.

In conclusion, CSF tau protein concentration seems to be an additional useful marker in differentiating CJD from AD. It should be noted that the 14-3-3 protein test is not pathognomonic, being $92 \%-96 \%$ specific among dementias. ${ }^{14}$ As tau protein is increased early in the course of the dementing illnesses it can be helpful in diagnosis of CJD.

1 Zeidler M, Gibbs C, Meslin F. WHO Manual for strengthening diagnosis and surveillance of Creutzfeldt-fakob disease 1998:7-8, 47-51

2 Vandermeeren $M$, Mercken M, Vanmechelen E, et al. Detection of $\tau$ proteins in normal and Alzheimer's disease cerebrospinal fluid with a sensitive sandwich enzymelinked immunosorbent assay. F Neurochem 1993;61:182834 .

3 Motter R, Vigo-Pelfrey C, Kholodenko D, et al. Reduction of $\beta$-amyloid peptide ${ }_{42}$ in the cerebrospinal fluid of patients with Alzheimer's disease. Ann Neurol 1995;38:643-8.

4 Hulstaert F, Blennow K, Ivanoiu A, et al. Improved discrimination of $\mathrm{AD}$ pateints using $\beta$-Amyloid (1-42) and tau levels in CSF. Neurology 1999;52:1555-62.

5 Hainfellner JA, Wanschitz J, Jellinger K, et al. Coexistence of Alzheimer-type neuropathology in Creutzfeldt-Jakob disease. Acta Neuropathol 1998;96:116-22.

6 Barcikowska M, Kwiecinski H, Liberski PP, et al. Barcikowska M, Kwiecinski H, Liberski PP, et al.
Creutzfeldt-Jakob disease with Alzheimer-type A betaCreutzfeldt-Jakob disease with Alzheimer-type A beta-
reactive amyloid plaques. Histopathology 1995;26:445-50.

7 McKhann G, Drachman D, Folstein M, et al. Clinical diagnosis of Alzheimer's disease. Report of the NINCDSADRDA work group under the auspices of the Department of Health and Human Services Task Force on Alzheimer's disease. Neurology 1984;34:939-44.

8 Otto M, Wiltfang J, Tumani H, et al. Elevated levels of tauprotein in cerebrospinal fluid of patients with CreutzfeldtJakob disease. Neurosci Lett 1997;225:210-12.

9 Otto M, Esselmann H, Schulz-Schaeffer W, et al. Decreased $\beta$-amyloid in cerebrospinal fluid of patients with Creutzfeldt-Jakob disease. Neurology 2000;54:1099-102.

10 Kanemaru K, Kameda N, Yamanouchi H. Decreased CSF amyloid $\beta 42$ and normal tau levels in dementia with Lewy bodies. Neurology 2000;54:1875-6.

11 Tapiola T, Overmyer M, Lehtovirta M, et al. The level of cerebrospinal fluid tau correlates with neurofibrillary tangles in Alzheimer's disease. Neuroreport 1977;8:3961-3.

12 Kapaki E, Paraskevas GP, Michalopoulou M, et al. CSF tau is increased in multiple sclerosis. Eur Neurol 2000;43:22832 .

13 Small DH, McLean CA. Alzheimer's disease and the amyloid $\beta$ protein: what is the role of amyloid? $\mathcal{F}$ Neurochem 1999;73:443-9.

14 Zerr I, Bodemer M, Gefeller O, et al. Detection of 14-3-3 protein in the CSF supports the diagnosis of CreutzfeldtJakob disease. Ann Neurol 1998;43:32-40. 